\title{
Characterizations and Quantitative Estimation of Alkali-Activated Binder Paste from Microstructures
}

\author{
Arkamitra Kar ${ }^{1), *}$, Indrajit Ray ${ }^{2)}$, Udaya B. Halabe ${ }^{1)}$, Avinash Unnikrishnan ${ }^{1)}$, \\ and Ben Dawson-Andoh ${ }^{3)}$
}

(Received September 19, 2013, Accepted January 6, 2014)

\begin{abstract}
Alkali-activated binder ( $\mathrm{AAB}$ ) is recently being considered as a sustainable alternative to portland cement (PC) due to its low carbon dioxide emission and diversion of industrial wastes and by-products such as fly ash and slag from landfills. In order to comprehend the behavior of $\mathrm{AAB}$, detailed knowledge on relations between microstructure and mechanical properties are important. To address the issue, a new approach to characterize hardened pastes of AAB containing fly ash as well as those containing fly ash and slag was adopted using scanning electron microscopy (SEM) and energy dispersive X-ray spectra microanalyses. The volume stoichiometries of the alkali activation reactions were used to estimate the quantities of the sodium aluminosilicate $(\mathrm{N}-\mathrm{A}-\mathrm{S}-\mathrm{H})$ and calcium silicate hydrate $(\mathrm{CSH})$ produced by these reactions. The 3D plots of $\mathrm{Si} / \mathrm{Al}, \mathrm{Na} / \mathrm{Al}$ and $\mathrm{Ca} / \mathrm{Si}$ atom ratios given by the microanalyses were compared with the estimated quantities of $\mathrm{CSH}(\mathrm{S})$ to successfully determine the unique chemical compositions of the $\mathrm{N}-\mathrm{A}-\mathrm{S}-\mathrm{H}$ and $\mathrm{CSH}(\mathrm{S})$ for ten different $\mathrm{AAB}$ at three different curing temperatures using a constrained nonlinear least squares optimization formulation by general algebraic modeling system. The results show that the theoretical and experimental quantities of $\mathrm{N}-\mathrm{A}-\mathrm{S}-\mathrm{H}$ and $\mathrm{CSH}(\mathrm{S})$ were in close agreement with each other. The $R^{2}$ values were 0.99 for both alkali-activated fly ash and alkali-activated slag binders.
\end{abstract}

Keywords: alkali-activated binder, characterization, microstructure, optimization.

\section{Introduction}

Portland cement (PC), the main binder of concrete, emits substantial amount of $\mathrm{CO}_{2}$ and reduces nature's resource of limestone during its manufacture (Provis and van Deventer 2009). So, rapid development of infrastructure is likely to hinder sustainable development which necessitates development of an alternative material to reduce the demand for $\mathrm{PC}$ and decrease in $\mathrm{CO}_{2}$ emission. A possible solution to this problem might be the use of alkali-activated binder (AAB) or inorganic polymers binder. Inorganic polymers are alumino-silicate materials which exhibit excellent physical and chemical properties and a diverse range of potential applications in infrastructures, including precast structures and non-structural elements, and concrete pavements and related products. In 1981, inorganic polymeric materials were

\footnotetext{
${ }^{1)}$ Civil and Environmental Engineering, West Virginia University, Morgantown, WV 26506, USA.

*Corresponding Author; E-mail: akar1@mix.wvu.edu

${ }^{2)}$ Civil Engineering, Purdue University Calumet, Hammond, IN 46323, USA.

${ }^{3)}$ Wood Science and Technology, Division of Forestry and Natural Resources, West Virginia University, Morgantown, WV 26506, USA.

Copyright $\odot$ The Author(s) 2014. This article is published with open access at Springerlink.com
}

produced by mixing alkalis with burnt mixture of kaolinite, limestone and dolomite (Davidovits 1982). The binders were known as "geopolymer" since they were originated by inorganic poly-condensation, or "geo-polymerization" (Davidovits 1982, 1994). This process is also known as alkali activation of aluminosilicate materials.

During the past two decades, AAB have attracted strong interests all over the world due to their advantages of low energy cost, appreciable serviceability, and good durability compared to PC concrete (Shi et al. 2006; Davidovits 1988; Smith and Comrie 1988; Davidovits 1991). A major incentive for further development of such $\mathrm{AAB}$ is created by the annual output of fly ashes from power plants and other byproduct materials, such as slag, which is so enormous that there is a constant need to find new uses for them.

Literature review shows that X-ray diffraction (XRD) revealed limited information due to the substantial amorphous nature of $\mathrm{AAB}$ microstructure. In case of fly ash precursor, the main crystalline phases detected from XRD were quartz $\left(\mathrm{SiO}_{2}\right)$, mullite $\left(\mathrm{Al}_{2} \mathrm{O}_{3}\right)$, magnetite and hematite $\left(\mathrm{Fe}_{2} \mathrm{O}_{3}\right)$. The humps in XRD patterns of $\mathrm{AAB}$ reaction products were different from that in the original fly ash, which indicated the dissolution of fly ash glass phases and formation of amorphous structure in the AAB matrix (Van Jaarsveld 2000; Davidovits 1983). A distinguishing feature between the raw precursor reference sample $(\mathrm{Si} / \mathrm{Al}=1.95)$ and the other $\mathrm{AABs}$ $(\mathrm{Si} / \mathrm{Al}=2.2)$ is the formation of hydroxy sodalite, a low silica zeolite $\left(\mathrm{Na}_{6}\left(\mathrm{Si}_{6} \mathrm{Al}_{6} \mathrm{O}_{24}\right) \cdot 8 \mathrm{H}_{2} \mathrm{O}\right)$. In the recent years, several 
aluminosilicate minerals have been examined through Fourier Transform Infra-Red (FTIR) spectroscopy (Rees et al. 2004; Breck 1974). Majority of the results were concerned with the behavior of the ( $\mathrm{Si}, \mathrm{Al}-\mathrm{O})$ band, which is found close to the $1,000 \mathrm{~cm}^{-1}$ (Barbosa et al. (2000), and Lee and van Deventer (2002)). Scanning electron microscopy (SEM) imaging showed that the microstructure was made up of a number of spherical vitreous particles of various sizes in the range of 10 $200 \mu \mathrm{m}$. The spheres were hollow in general but some of them contained other particles of smaller size inside them. The primary reaction product resulting from the alkali activation was a sodium silicate gel that gave rise to the cementitious matrix. Some small fly ash particles which have already reacted with the alkaline liquid coexisted with the unreacted particles and even with the spherical particles partially covered with the reaction products (Muzek et al. 2012). Those spherical particles which were covered by the reaction products slowed down the degree of reaction. Energy dispersive X-ray spectra (EDS) analysis of gel showed majority of the phases containing $\mathrm{Na}-\mathrm{Si}-\mathrm{Al}$ in the bulk region suggesting the formation of silicate-activated gel by polymerization throughout the inter particles volume (De Silva et al. 2007; Lloyd et al. 2009). The properties of AAB systems depend not only on the composition and reactivity of the fly ash used, but also on the initial $\mathrm{SiO}_{2} / \mathrm{Al}_{2} \mathrm{O}_{3}$ ratio in the mixture. Pre-processing (e.g. fine grinding etc.) and/or use of a combination of raw materials of different reactivity, as well as selection of an activator in a $\mathrm{AAB}$ system are required to achieve the desired product properties (Muzek et al. 2012).

Although several researchers have conducted studies on the microstructural aspects of AAB using Scanning electron microscopy (SEM) and energy dispersive X-ray (EDS), Xray diffraction (XRD), Fourier Transform Infrared Spectroscopy (FTIR) as mentioned above, their primary focus of the research was to understand the underlying mechanisms of reactions and morphology of this complex system (Van Jaarsveld 2000; Davidovits 1983; Rees et al. 2004; Breck 1974; Barbosa et al. 2000; Lee and van Deventer 2002). No systematic studies on quantifying the volume fractions of alkali-activated binder products from the microanalysis and volume stoichiometry of the reaction products were reported. Limited researches have been conducted to understand the interactions of alkali-activated binder pastes from the fly ash and calcium-silicate-hydrate paste from slag. Based on the above limitations, the following studies were performed to first understand the interactions of $\mathrm{AAB}$ made with fly ash and slag and then estimate their volume fractions using combined microanalysis and optimization techniques. The following steps were followed: (i) Identifed the chemistry of polymerization, (ii) Studed the effect of pre-blending the starting materials, (iii) Obtained the optimum combination of precursor and activating solution and also identifying the mixture which provides the best compressive strength, and (iv) Developed a combined microanalysis and optimization technique to quantify the volume fractions of the different products of alkali activation of fly ash and slag precursors.

The volume fraction estimation was made for ten mixtures containing different percentages of fly ash and slag cured at each of three different temperatures using combined microanalysis and optimization technique applying general algebraic modeling system (GAMS). It is expected that the result of this study will ultimately help to estimate the paste volumes of various unknown $\mathrm{AAB}$ mixtures produced from different sources of fly ash and slag. The materials used in the present study and the experimental methods adopted have been presented in the following section.

\section{Materials and Experimental Methods}

\subsection{Materials}

Class F fly ash used in this study conforming to ASTM C618 (2013) (Standard Specification for Coal Fly Ash and Raw or Calcined Natural Pozzolan for Use in Concrete), was obtained from a local coal power plant. The specific gravity, specific surface area and oxide composition are listed in Table 1. Ground granulated blast furnace slag or slag conforming to Grade 100 of ASTM C989 (2013) (Standard Specification for Slag Cement for Use in Concrete and Mortars) obtained from local steel plant were used in this study (Table 1). The coarse aggregate used was $12.5 \mathrm{~mm} \mathrm{(1/2}$ in.) graded and crushed limestone conforming to ASTM C33/C33M-13 (Standard Specification for Concrete Aggregates). The saturated surface dry (SSD) bulk specific gravity was 2.68. Locally available $4.75 \mathrm{~mm}$ (0.187 in.) graded river sand conforming to ASTM C33/C33M-13 (2013) was used for this study. The fineness modulus and the SSD bulk specific gravity of sand were 2.79 and 2.59 , respectively. A commercially available high-range water reducing admixture (HRWRA), conforming to ASTM C494 Type F (2013) (Specification for Chemical Admixtures for Concrete), was used in this study.

\subsection{Mix Proportions}

The mix proportions were selected in order to compare their influences on the microstructural properties of the cementitious systems for different combinations of fly ash with slag replacement, at different ages and different temperatures. The starting materials can be categorized into two groups - precursor and activating solution. As the precursors are primarily composed of industrial by-products, they will lead to lots of uncertainties in the characteristics of the finished product. Moreover, the activating solution reacts with the precursor through a polymerization mechanism, whose chemistry is yet to be fully decoded. This polymerization process governs the development of strength of the building material and it is dependent on several factors - (i) the ratio of $\mathrm{SiO}_{2} / \mathrm{Na}_{2} \mathrm{O}$ in the activating silicate solution $(2: 1$ in this case); (ii) the ratio of $\mathrm{SiO}_{2} / \mathrm{Na}_{2} \mathrm{O}$ in the precursor-activating solution mixture (also known as Ms ratio or Ms modulus); (iii) the ratio of $\mathrm{SiO}_{2} / \mathrm{Al}_{2} \mathrm{O}_{3}$ in the precursor $(2.1$ in this case); (iv) the ratio of water-to-AAB solids (w/s) (0.20 in this case); and (v) the curing temperature, i.e., the temperature at which the polymerization is allowed to occur. The mixture proportions used in the present study have been 
Table 1 Properties of the materials used in this study.

\begin{tabular}{|c|c|c|}
\hline Materials & Slag $^{\mathrm{a}}$ & Fly ash \\
\hline Specific gravity & 2.88 & 2.47 \\
\hline Specific surface $\left(\mathrm{m}^{2} / \mathrm{kg}\right)$ & 580 (Blaine) & 490 (Blaine) \\
\hline Loss on ignition, $\%$ & 0.06 & 3.00 \\
\hline $\mathrm{SiO}_{2}, \%$ & 36.0 & 49.34 \\
\hline $\mathrm{Al}_{2} \mathrm{O}_{3}, \%$ & 12.0 & 22.73 \\
\hline $\mathrm{CaO}, \%$ & 42.0 & 3.09 \\
\hline $\mathrm{MgO}, \%$ & 6.0 & 1.06 \\
\hline $\mathrm{SO}_{3}, \%$ & 0.2 & 0.97 \\
\hline $\mathrm{Na}_{2} \mathrm{O}+0.685 \mathrm{~K}_{2} \mathrm{O}, \%$ & 0.74 & 2.75 \\
\hline $\mathrm{Fe}_{2} \mathrm{O}_{3}, \%$ & 1.8 & 16.01 \\
\hline Others, $\%$ & 1.2 & 1.05 \\
\hline
\end{tabular}

${ }^{\mathrm{a}}$ The $\mathrm{pH}$ value (in water) for the slag is in the range of 10.5-12.7.

furnished in detail in Kar et al. (2013). They are summarized in Table 3.

For initial assessment to estimate the best Ms modulus, the compressive strengths of 2 in. cube specimens were measured for different $\mathrm{AAB}$ mixtures as shown in Table 2. It was observed that Ms modulus of 1.4 resulted in the best compressive strengths at all ages and the strengths increased with curing temperature. A total of 10 mixes were produced at each of three different temperatures-23, 40 and $60{ }^{\circ} \mathrm{C}$, using different combinations of fly ash, and slag (Table 3 ). Thus a total of 30 different mixes were used for the present study.

\subsection{Experimental Program}

In this study SEM/EDS and degree of reaction tests were conducted for quantitative identification of the microstructural characteristics of AAB binders. The XRD and FTIR were conducted to qualitatively understand the underlying mechanism of the reactions of various alkali-activated binders and their nature of products.

\subsubsection{XRD and FTIR}

Powder XRD was performed on all samples using a Bruker D8 Discovery X-ray Diffractometer. The CuK $\alpha$ Xrays were generated at $40 \mathrm{~mA}$ and $40 \mathrm{kV}$. FTIR spectra were obtained using a PerkinElmer Spectrum 100 FTIR spectrometer with Universal ATR accessory, in absorbance mode, within the frequency range of $4,000-400 \mathrm{~cm}^{-1}$. As mentioned previously, the present study requires knowledge about the quantity of the different phases in the microstructure of the polymer product. Thus SEM/EDS techniques were implemented for further quantification of the phases which were confirmed to be present in the AAB microstructure through the XRD and FTIR studies.

\subsubsection{SEM/EDS}

A state-of-the-art thermal Field Emission Scanning Electron Microscope (FE-SEM), JSM-7600F (accompanied by an EDS analyzer), supplied by JEOL Limited was used for the imaging process. The samples were then polished mechanically and the final average thickness was about $2.5 \mathrm{~mm}$. Before SEM and microanalysis by EDS, the specimens were allowed to dry at $50 \%$ humidity and $40{ }^{\circ} \mathrm{C}$ for $48 \mathrm{~h}$ in an environmental chamber to reduce the time of vacuum. Then they were coated with a $15 \mathrm{~nm}$ layer of platinum in argon gas atmosphere at a high vacuum of $5.0 \times 10^{-6}$ Torrs, in order to make them electrically conductive in nature. The samples were stored in $99.8 \%$ laboratory grade methanol in air-tight vial until the SEM studies were conducted to stop the continued hydration at respective ages. In order to get good resolution for the SEM/EDS the surfaces of the specimens had to be polished before the microanalyses. The specimens were polished using a TegraPol-31 fitted with Tegra Force 5 machine by Struers Inc.

\subsubsection{Degree of Reaction at Different Ages}

One of the major factors that govern the progress of polymerization is the curing temperature. Hence, it is of utmost importance to have knowledge of the influence of the curing temperature on the degree of reaction. The technique suggested by Fernandez-Jimenez et al. (2006) was followed to determine the degree of reaction. After curing (at each respective temperature), the alkali activated fly ash was reacted with 1:20 $\mathrm{HCl}$ (supplied by Fisher Scientific) to determine the amount of fly ash that had been converted to sodium aluminosilicate phase and the portion that had not reacted with the alkaline solutions to determine the degree of reaction, $\alpha . \mathrm{HCl}$ reaction provokes the dissolution of the chief reaction products of the alkali activation of fly ash (alkaline aluminosilicate gel and zeolites) in the acid, while the fraction of ash not activated by the alkalis remains in the insoluble residue. The experimental procedure followed in the acid attack involved adding $1 \mathrm{~g}$ of activated fly ash to a beaker containing $250 \mathrm{~mL}$ of $(1: 20) \mathrm{HCl}$. The mixture was stirred with a plastic rotor for $3 \mathrm{~h}$, after which it was filtered and washed with de-ionized water to a neutral $\mathrm{pH}$. The 
Table 2 Preliminary Scheme for Selection of Precursor Combinations.

\begin{tabular}{c|c|c|c}
\hline Precursor & $\begin{array}{c}\text { Alkali activating solution, AAS } \\
\left(\mathrm{Na}_{2} \mathrm{O} \cdot 2 \mathrm{SiO}_{2}+\mathrm{NaOH}\right)\end{array}$ & Curing temps & Age (days) \\
\hline \hline $100 \%$ Fly ash & $\begin{array}{c}\text { Total } \mathrm{SiO}_{2} / \mathrm{Na}_{2} \mathrm{O}=1.2,1.4,1.6, \\
1.8\end{array}$ & $23,40,60{ }^{\circ} \mathrm{C}$ & $3,7,28$ \\
\hline
\end{tabular}

Table 3 Final concrete mix proportions for alkali activated fly ash and/or slag (Ms modulus =1.4).

\begin{tabular}{|c|c|c|c|}
\hline Precursor & Mixture name & Fly ash $\left(\mathrm{kg} / \mathrm{m}^{3}\right)$ & Slag $\left(\mathrm{kg} / \mathrm{m}^{3}\right)$ \\
\hline $100 \%$ Fly ash & FA 100 & 400 & 0 \\
\hline $85 \%$ Fly ash $+15 \%$ slag & FA 85 SG 15 & 340 & 60 \\
\hline $70 \%$ Fly ash $+30 \%$ slag & FA 70 SG 30 & 280 & 120 \\
\hline $50 \%$ Fly ash $+50 \%$ slag & FA 50 SG 50 & 200 & 200 \\
\hline $30 \%$ Fly ash $+70 \%$ slag & FA 30 SG 70 & 120 & 280 \\
\hline $15 \%$ Fly ash $+85 \%$ slag & FA 15 SG 85 & 60 & 340 \\
\hline $100 \%$ slag & SG 100 & 0 & 400 \\
\hline $\begin{array}{l}\text { Pre blend } 100 \% \text { fly ash and solid } \\
\mathrm{NaOH} \text { for } 15 \text { days }\end{array}$ & FA $100 \mathrm{p} 15$ & 400 & 0 \\
\hline $\begin{array}{l}\text { Pre blend } 100 \% \text { fly ash and solid } \\
\mathrm{NaOH} \text { for } 30 \text { days }\end{array}$ & FA $100 \mathrm{p} 30$ & 400 & 0 \\
\hline $\begin{array}{c}\text { Pre blend } 100 \% \text { fly ash and solid } \\
\mathrm{NaOH} \text { for } 60 \text { days }\end{array}$ & FA 100 p 60 & 400 & 0 \\
\hline
\end{tabular}

Note The quantity of coarse aggregate was kept constant at $1,209 \mathrm{~kg} / \mathrm{m}^{3}$ and that of fine aggregate at $651 \mathrm{~kg} / \mathrm{m}^{3}$ for all mixes. Quantity of Sodium silicate (liquid) was $129.43 \mathrm{~kg} / \mathrm{m}^{3}$ and that of sodium hydroxide (solid) was $10.57 \mathrm{~kg} / \mathrm{m}^{3}$ for all mixes. The quantity of HRWRA used was in the range of $5,060-6,745 \mathrm{~mL} / \mathrm{m}^{3}$.

insoluble residue was first dried at $100{ }^{\circ} \mathrm{C}$ and then at $1,000{ }^{\circ} \mathrm{C}$; the degree of reaction, $\alpha_{\mathrm{FA}}$, was found by determining weight loss. A temperature of $1,000{ }^{\circ} \mathrm{C}$ was attained using an Isotemp Muffle Furnace from Fisher Scientific. The results of the different experiments are presented in the next section.

\section{Experimental Results and Analytical Techniques}

XRD diffractogram for a 28-day AAB specimen containing $100 \%$ fly ash with Ms modulus $=1.4$, curing temperature of $40{ }^{\circ} \mathrm{C}$, and $\mathrm{w} / \mathrm{s}=0.20$ showed predominantly $\mathrm{X}$ ray amorphous character. Peaks of quartz $\left(\mathrm{SiO}_{2}\right)$ and mullite $\left(\mathrm{Al}_{6} \mathrm{Si}_{2} \mathrm{O}_{13}\right)$ were visible along with those of analcime $\left(\mathrm{NaAlSi}_{2} \mathrm{O}_{6} \cdot \mathrm{H}_{2} \mathrm{O}\right)$ and hydroxy sodalite $\left(\mathrm{Na}_{6}\left(\mathrm{Si}_{6} \mathrm{Al}_{6} \mathrm{O}_{24}\right)\right.$. $\left.8 \mathrm{H}_{2} \mathrm{O}\right)$. Those peaks showed the presence of sodium aluminate chemical bonds having ( $\mathrm{Si}-\mathrm{O}-\mathrm{Al})$ chemical structure. Peaks were also observed for analcime and hydroxy sodalite where the $\mathrm{Na}^{+}$cation has penetrated into the aluminosilicate $(\mathrm{Si}-\mathrm{O}-\mathrm{Al})$ chemical structure. Polymerization proceeded as $\mathrm{Na}^{+}$entered into the $\mathrm{Si}-\mathrm{O}-\mathrm{Al}$ structures. The hump or the shoulder in the diffractogram confirmed the presence of amorphous phases co-existing with crystalline phases. These observations were in close agreement with the findings from previous researchers (Rees et al. 2004; Kupwade-Patil and Allouche 2011; Kamhangrittirong et al. 2007). In the case of samples containing either slag or a combination of fly ash and slag as precursor, presence of $\mathrm{C}-\mathrm{S}-\mathrm{H}(\mathrm{S})$ was observed from the small peaks which represented the amorphous calcium silicate hydrate $(\mathrm{CSH})$ matrix. These observations were in agreement with the findings from previous researchers (Skvara et al. 2006; Sakulich 2009). FTIR spectra were collected for both the precursor (fly ash powder) and the finished product (28-day age AAB specimen with $100 \%$ fly ash at Ms modulus of 1.4 and $\mathrm{w} / \mathrm{s}=0.2$ ). The spectra for $\mathrm{AAB}$ containing $100 \%$ fly ash at $23{ }^{\circ} \mathrm{C}$ shows a chemical shift of about $10 \mathrm{~cm}^{-1}$ in the range of wave number of $1,008 \mathrm{~cm}^{-1}$. This shows the progress of the polymerization reaction. Also, the spectra for AAB with $100 \%$ fly ash at $60{ }^{\circ} \mathrm{C}$ show a chemical shift w.r.t. the spectra corresponding to the AAB with $100 \%$ fly ash at $40{ }^{\circ} \mathrm{C}$. In other words, the chemical shift increased with the increase in curing temperature. This was an indication of the increased rate of reaction with the increase in curing temperature. The results are consistent with the research findings of Barbosa et al. (2000) and Rees (2007). Presence of $\mathrm{Al}-\mathrm{OH}$ bonds were also detected in each of the AAB spectra in the region of $910 \mathrm{~cm}^{-1}$. Peaks associated with amorphous silica appeared at around 1,000, 900 and $500 \mathrm{~cm}^{-1}$, these peaks corresponded to the stretching, 
bending and rocking of the $\mathrm{Si}-\mathrm{O}-\mathrm{Si}$ bond, respectively. The silica peak near $1,000 \mathrm{~cm}^{-1}$ was observed at $1,043 \mathrm{~cm}^{-1}$ for the raw fly ash powder. This wave number was taken as the datum with respect to which the peak shifts for all the AAB samples were calculated. SEM images for further microstructural characterization are shown below.

Figures $1 \mathrm{a}$ and $1 \mathrm{~b}$ show the typical microstructural features of FA $100 \mathrm{AAB}$ specimens at three different temperatures and two different magnifications at each temperature. In general, the microstructure of the FA 100 AAB specimens was highly inhomogeneous and primarily made up of the reaction product resulting from the alkali activation-a sodium aluminosilicate gel that gave rise to the cementitious matrix. The matrix was full of loosely structured fly ash grains of different sizes. Numerous circular cavities belonging to fly ash particles were evident in the gel. The surroundings of the cavities consisted of tubular vitreous network (Figs. 1a and 1b). Some small fly ash particles which have already been reacted with the alkaline liquid, coexisted with the unreacted particles (spherical vitreous particles of various sizes in the range of 10-200 $\mu \mathrm{m}$ ). There were also some spherical particles partially covered with the reaction products which consequently reduced the rate of reaction to some extent. The considerable amount of unreacted spheres, as well as the presence of pores in the matrix indicated incomplete reaction. The amount of sodium aluminosilicate gel present in the cementitious matrix was found to increase with rise in curing temperature. Thus it corroborated the findings from the FTIR studies that the degree of reaction increased at higher temperature. The unreacted spherical particles of FA 100 specimens indicated incomplete reaction which confirmed the low degree of reaction values (about $28.9 \%$ after 28 days for a curing temperature of $40{ }^{\circ} \mathrm{C}$ ). The patterns observed in the case of the present study are in agreement with the results obtained by Skvara et al. (2006), Provis and van Deventer (2009), Kupwade-Patil and Allouche (2011), and Muzek et al. (2012). The influence of adding $\mathrm{Ca}^{2+}$ ions through partial or full replacement of fly ash by slag can be observed in Figs. $2 \mathrm{a}-2 \mathrm{~d}$.

Typical microstructural features of (i) FA 50 SG 50 (Fig. 2a, b), and (ii) SG 100 AAB (Fig. 2c, d) samples cured at $40{ }^{\circ} \mathrm{C}$ temperature have been shown at two different magnifications for each case. The patterns observed in the case of the present study are in agreement with the results obtained by Skvara et al. (2006). The C-S-H(S) was identified through SEM morphology from their fibrous to irregular grains forming reticular network. Thus sodium aluminosilicate matrix due to alkali activation of fly ash coexisted with $\mathrm{C}-\mathrm{S}-\mathrm{H}(\mathrm{S})$ formation due to slag hydration. In the case of the preblended AAB samples, the SEM revealed morphologies similar to the normal AAB mixes. The images have not been provided here for brevity. SEM observations were only good enough for qualitative characterization of the AAB microstructure by identification of the various chemical phases present there. As the present study required
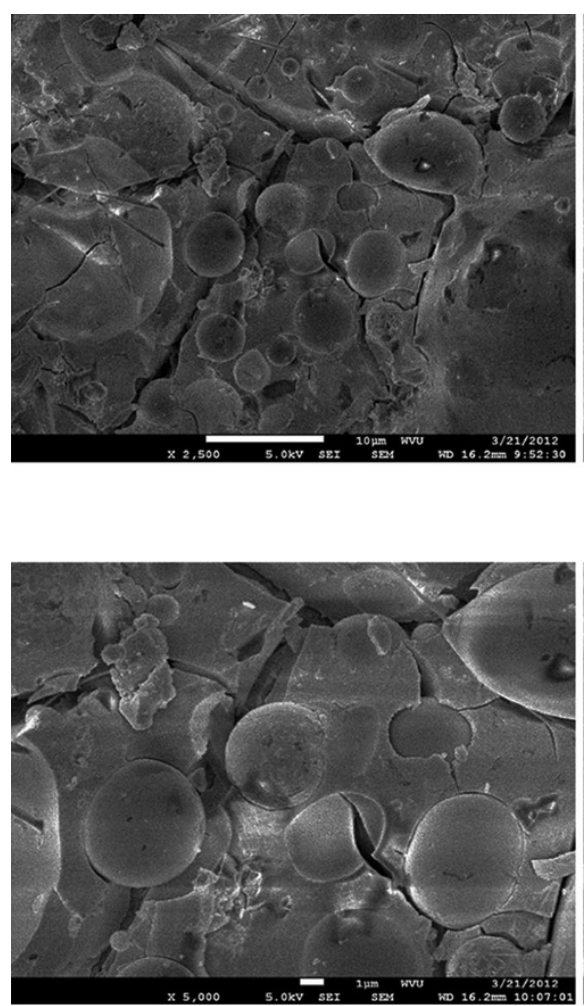
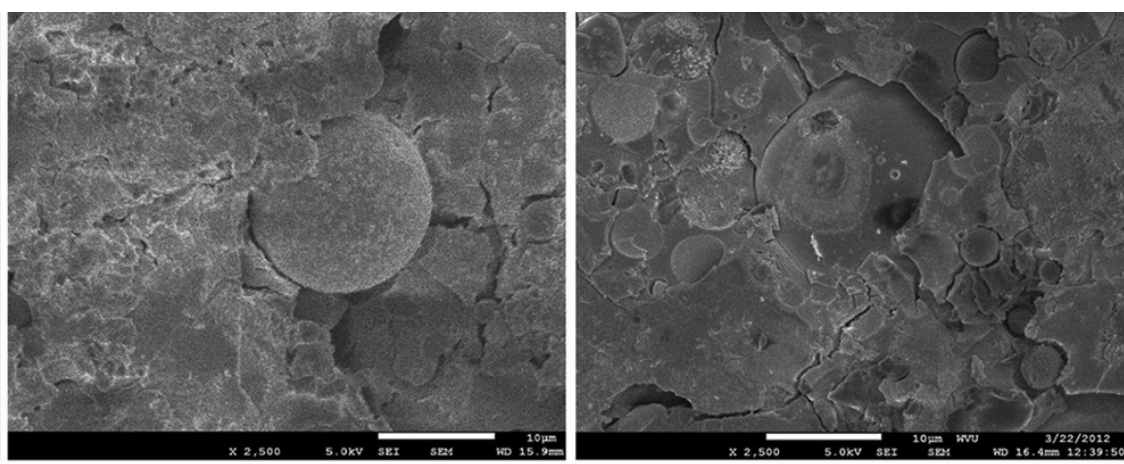

(a)
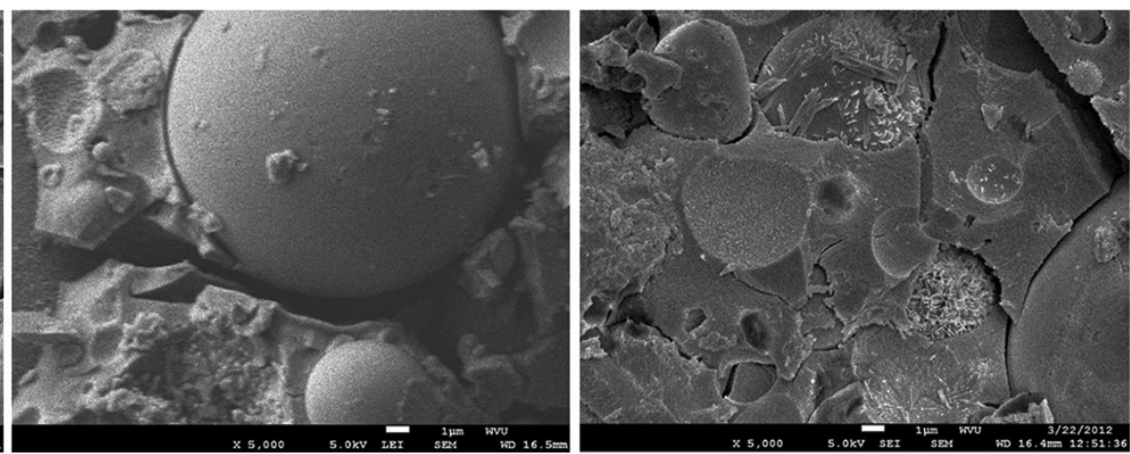

(b)
Fig. 1 SEM images of 28-days old FA 100 AAB paste specimens at two different magnifications-a 2,500x and b $5,000 \times$ [ $L$ to $R \rightarrow 23,40$, and $60^{\circ} \mathrm{C}$ ]. Five different points were scanned at nine different locations on each specimen at each magnification to obtain a total of 90 data points in each case. 
FA 50 SG 50

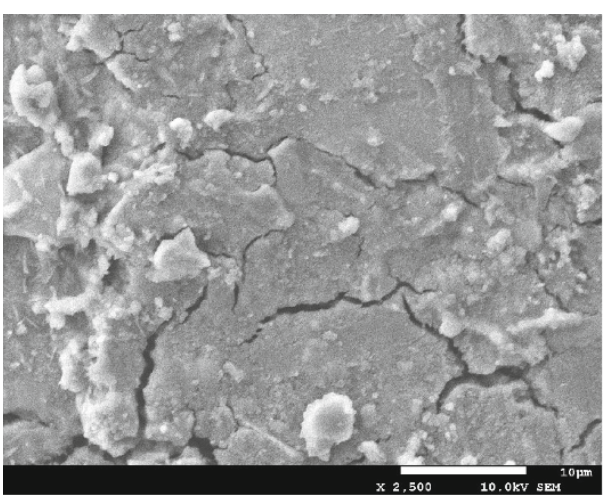

(a) $2500 \mathrm{x}$

SG 100

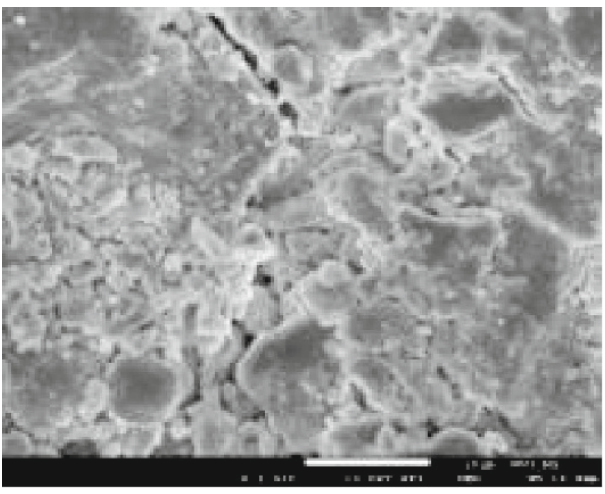

(c) $2500 x$

Fig. 2 SEM images of 28-days old AAB paste specimens cured at $40{ }^{\circ} \mathrm{C}$ and at two different magnifications$2,500 \times$ and $5,000 \times$ : a and b FA 50 SG 50, and $\mathbf{c}$ and $\mathbf{d}$

quantitative knowledge of the chemical phases present in the microstructure of the $\mathrm{AAB}$ samples, EDS analyses were conducted.

For each location, five EDS spectra were acquired with the help of the INCA systems software that is used by the Oxford spectrometer. The working distance was maintained at $15 \mathrm{~mm}$ and the probe current $8(65.4-67.0 \mu \mathrm{A})$ in order for the EDS analyzer to work properly. Each sample was approximately divided in three locations. The microanalysis was done at five randomly chosen points for each location at each magnification for every sample. Thus for each sample, for three locations, at each magnification, 45 points were analyzed. Finally for two magnifications $(2,500 \times$ and $5,000 \times), 90$ points were analyzed for each of the ten different mixes at every age $(7,28$, and 90 days). The points for microanalysis were chosen randomly to minimize the influence of the heterogeneity of the AAB microstructure. In selected locations of sample, also average microanalysis (not point analysis) was conducted to verify the variations compared to point analysis. Out of the 90 points, 60 points were used to formulate the model used for estimating the volume of the hydrated products and the remaining 30 points were used to validate the predictions from the proposed model. These 60 points were chosen randomly for the same reason as mentioned above. As a typical example for a given mixture proportion and $2500 \times$ magnification,

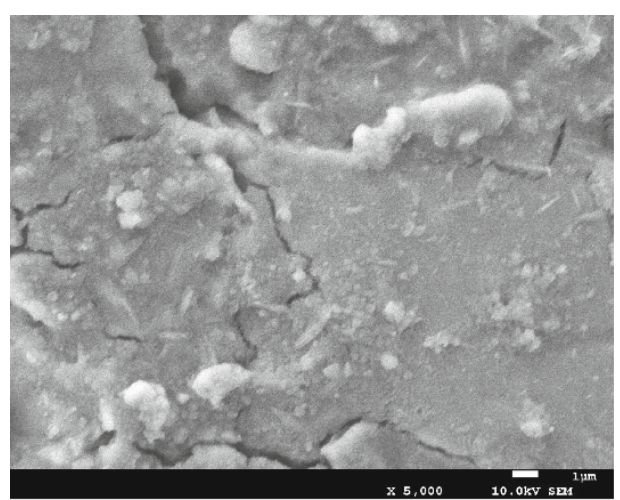

(b) $5000 \mathrm{x}$

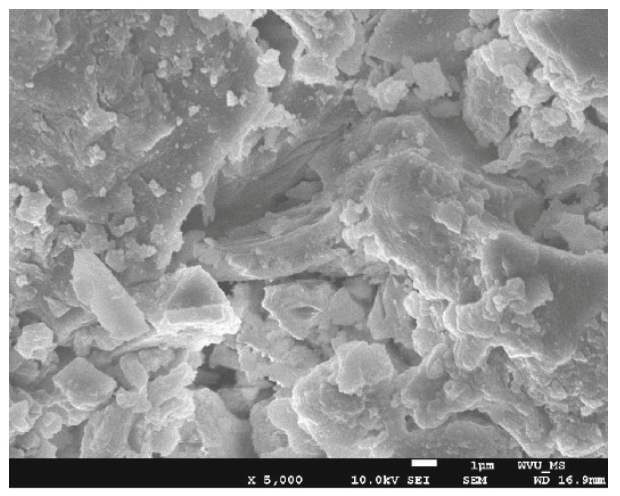

(d) $5000 \mathrm{x}$

SG 100. Five different points were scanned at nine different locations on each specimen at each magnification to obtain a total of 90 data points in each case.

Figs. $3 a$ and $3 b$ show EDS images for FA 100 AAB matured paste and FA 50 SG 50 AAB matured paste with curing temperature of $40{ }^{\circ} \mathrm{C}$. A similar procedure was followed for the other cases. The matured alkali activated material pastes were observed under the SEM at two different magnifications $-2500 \times$ and $5000 \times$. EDS analyses showed that the matrix primarily consisted of the phases containing $\mathrm{Na}-\mathrm{Si}-\mathrm{Al}$ in the bulk region in case of the specimens where fly ash was the main precursor. In addition to $\mathrm{Na}, \mathrm{Si}$ and $\mathrm{Al}$, traces of $\mathrm{Fe}$, $\mathrm{Ca}, \mathrm{K}$ and $\mathrm{Mg}$ were also observed in these specimens. These remnants $(\mathrm{Fe}, \mathrm{Ca}, \mathrm{K}, \mathrm{Mg})$ obviously represented the unreacted fly ash phases, which did not dissolve during alkali activation. When slag was present in greater amounts, the presence of $\mathrm{Ca}^{2+}$ was more prominent.

EDS microanalyses were carried out on a total of 90 data points for each sample as mentioned above. The results obtained from the microanalysis were in terms of the atomic percentages of the different elements present in the $\mathrm{AAB}$ microstructure. The $\mathrm{Si} / \mathrm{Al}, \mathrm{Na} / \mathrm{Al}$ and and $\mathrm{Ca} / \mathrm{Si}$ ratios were computed for each of the 90 data points. They were plotted on $3 \mathrm{D}$ axes using OriginPro 9 software (Figs. 4a-4c). The concept of 3D plot was used by Famy et al. (2003) to characterize the $\mathrm{C}-\mathrm{S}-\mathrm{H}$ and its phase compositions in case of PC mortars through the solution of simultaneous algebraic equations. The results of the works done by previous 


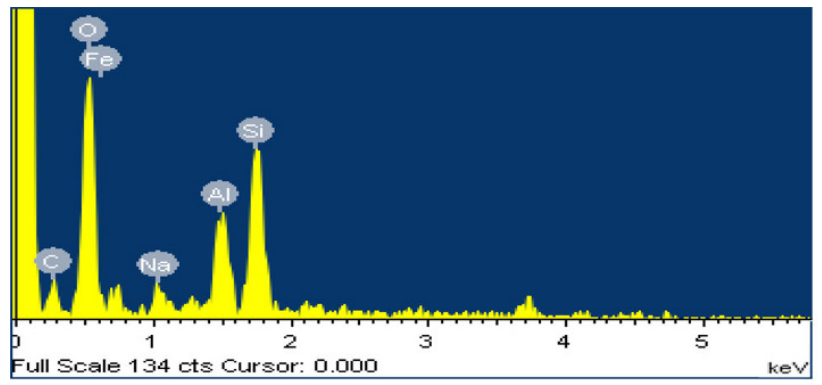

(a)

Fig. 3 EDS images of 28-days old $A A B$ paste specimens cured at $40{ }^{\circ} \mathrm{C}$ : a FA 100 and b FA 50 SG 50. Five different points were scanned at nine different locations

researchers showed that typical $\mathrm{AAB}$ composition proposed by Davidovits (1994) is generally expressed as $n M_{2} \mathrm{O}$ $\mathrm{Al}_{2} \mathrm{O}_{3} \cdot x \mathrm{SiO}_{2} \cdot y \mathrm{H}_{2} \mathrm{O} ; \quad$ where $1<n<1.6 ; \quad 2<x<3.5$; $3<y<7$; and $M$ : Na, K (Muzek et al. 2012). For the present study, the alkali activator comprised of sodium silicate solution and sodium hydroxide. Hence, $\mathrm{M}$ represents $\mathrm{Na}, n$ represents the $\mathrm{Na}_{2} \mathrm{O} / \mathrm{Al}_{2} \mathrm{O}_{3}$ molar ratio, and $x$ represents the $\mathrm{SiO}_{2} / \mathrm{Al}_{2} \mathrm{O}_{3}$ molar ratio.

From stoichiometry, it is evident that $1 \mathrm{~mol}$ of $\mathrm{Na}_{2} \mathrm{O}$ is equivalent to $2 \mathrm{~mol}$ of $\mathrm{Na} ; 1 \mathrm{~mol}$ of $\mathrm{Al}_{2} \mathrm{O}_{3}$ is equivalent to $2 \mathrm{~mol}$ of $\mathrm{Al}$ and $1 \mathrm{~mol}$ of $\mathrm{SiO}_{2}$ is equivalent to $1 \mathrm{~mol}$ of $\mathrm{Si}$. Hence the ranges for the oxide ratios mentioned above can be transformed to their equivalent elemental ratios as follows: $1<\mathrm{Na} / \mathrm{Al}$ (atomic ratio) $<1.6$ and $1<\mathrm{Si} / \mathrm{Al}<1.75$ (atomic ratio). These ranges will be used to analyze the results from the EDS analyses using the concept of 3-D plots as discussed in the following paragraph. The total number of points analyzed by EDS for each sample that comprised of $\mathrm{Si} / \mathrm{Al}$, and $\mathrm{Na} / \mathrm{Al}$ ratios in the given range and $\mathrm{Ca} / \mathrm{Si}$ ratios less than 0.1 were counted as representing the polymer product component of the total paste volume. It was assumed that the polymer products formed due to alkali activation of fly ash comprised of very low calcium content. Hence the $\mathrm{Ca} / \mathrm{Si}$ ratios for these products were assumed to be less than 0.1 .

As mentioned earlier in Sect. 4.2, the SEM/EDS microanalyses were carried out at randomly chosen points to account for the heterogeneity of the microstructure of the cement paste. Each of the scanned areas was approximately $120 \mu \mathrm{m}$ by $120 \mu \mathrm{m}$ square. The polymer product was detected from SEM morphology and features, both at early stage and later. They consisted of highly inhomogeneous structures and the matrix was full of loosely structured grains representing fly ash. Numerous circular cavities belonging to fly ash particles were evident in the matrix. Cavities were surrounded by tubular vitreous network. The ratio of the number of points representing the polymer product to the total number of data points for each sample was taken as the representative volume fraction of polymer for each sample. This approach was somewhat similar to the point-count procedure as proposed by Feng et al. (2004). This approach had been successfully applied by Kar et al. (2012a) for

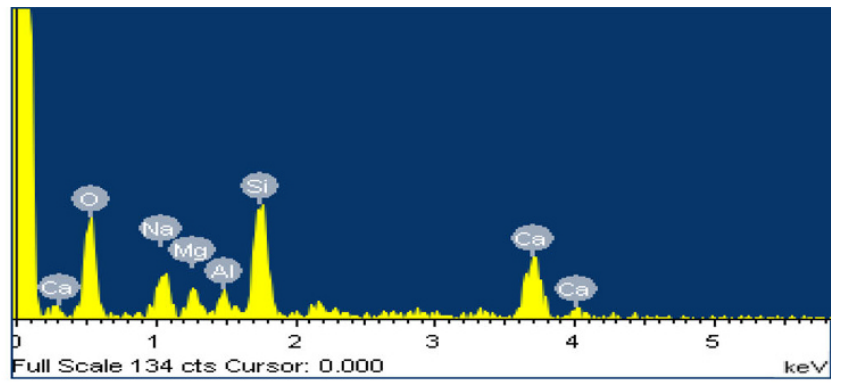

(b)

on each specimen at each of two different magnifications to obtain a total of 90 data points in each case.

systems containing PC along with different combinations of fly ash, slag and silica fume as supplementary cementitious materials. The volume fraction from SEM was compared with the results from the proposed algebraic equation and the square of the errors was minimized using optimization technique with the help of GAMS. The optimal $\mathrm{Na} / \mathrm{Al}$ and $\mathrm{Si} / \mathrm{Al}$ atomic ratios were obtained for each specimen. Thus, unique values of $n, x$ and $y$ were obtained which most nearly represents the chemical composition of the polymer product. Similar approach was followed to find the volume fraction of $\mathrm{CSH}(\mathrm{S})$ in case of mixtures containing slag in addition to fly ash. The range of $\mathrm{Ca} / \mathrm{Si}$ atom ratio in $\mathrm{CSH}(\mathrm{S})$ in case of slag cements is about 1.4-1.6 (Taylor 1997). Thus, from the 3D plots of the microanalysis data, the number of points at which the $\mathrm{Si} / \mathrm{Ca}$ ratio lies in the range of $\mathrm{CSH}(\mathrm{S})$ were counted and expressed as a fraction of the total number of data points. The volume fraction of the polymer product from the theoretical approach was computed using the $n, x$, and $y$ values derived from the optimization technique. This was compared with the experimental values in case of the mixtures with slag and they showed very good agreement as shown later in Sect. 4. Some example 3-D plots have been shown in Fig. 4 for the sake of brevity. The first set of plots depicts the results at different curing temperatures for 7-day old FA 100 AAB samples. An increase in the number of points representing the reaction product due to alkali activation of fly ash was generally observed when the curing temperature was increased for both FA 100 mixes as well as mixes containing partial or full replacement of fly ash with slag.

In the next section, volume stoichiometry and optimization will be combined to estimate the theoretical volume fractions. The comparisons between the experimentally obtained values and those obtained by the optimization technique for all the different mix proportions have been shown in the following section.

\subsection{Analysis of Microscale Test Results Using Volume Stoichiometry and Statistical Optimization}

The results of the different microscale experiments are analyzed and used to estimate the quantities of the reaction 
products of alkali activation of the precursors. A combination of optimization tools and the volume stoichiometry of the chemical reactions associated with the alkali activation of fly ash and/or slag was adopted for this purpose. The chemistry of the polymerization reaction produced by the alkali activation of fly ash was obtained from available literature. The volume stoichiometry associated with this reaction was used in the present study to calculate the amount of $\mathrm{AAB}$ products formed when fly ash was activated with alkalis. As the fly ash used in this study was locally available, the general formula for the $\mathrm{AAB}$ was expressed as $n \mathrm{Na}_{2} \mathrm{O} \cdot \mathrm{Al}_{2} \mathrm{O}_{3} \cdot x \mathrm{SiO}_{2} \cdot y \mathrm{H}_{2} \mathrm{O}$. Microanalysis using $\mathrm{SEM}$ and EDS were conducted to identify the approximate chemical composition of the $\mathrm{AAB}$ product. Optimization techniques were used on the microanalysis results and the estimated quantities of hydrated products to determine $n, x$, and $y$.

\subsubsection{Chemical Reactions During Alkali Activation of Fly Ash}

The schematic formation of AAB material can be shown as described by Eqs. (1) and (2).

\subsubsection{Reaction Mechanism of Alkali Activation of Slag}

When $\mathrm{Ca}^{2+}$ ions are added to fly ash (aluminosilicate) precursor, the alkali activation of the binders produce $\mathrm{CSH}$ and alkali earth alumino-silicates. These binders have been reported to attain hydraulic hardening without depending on hydration with water of binders containing a high content of basic calcium minerals like tricalcium silicate $\left(\mathrm{C}_{3} \mathrm{~S}\right)$, dicalcium silicate $\left(\mathrm{C}_{2} \mathrm{~S}\right)$, tricalcium aluminate $\left(\mathrm{C}_{3} \mathrm{~A}\right)$, and tetracalcium aluminoferrite $\left(\mathrm{C}_{4} \mathrm{AF}\right)$. Combinations of silica/ alumina sources as well as mixed alkali sources usually impart better properties due to optimum structure formation during hydration. Mixtures containing slag and fly ash activated with sodium hydroxide are low-cost binders with high early strength development. However, they showed high sensitivity to drying resulting in loss of tensile strength and fast carbonation. The mixes showed efflorescence of salts and irritation on skin contact. The binders also exhibited rapid setting. This was controlled by grinding the binder with small amounts of anhydrous lime, clinker, gypsum or phosphogypsum. The concrete properties were equal or

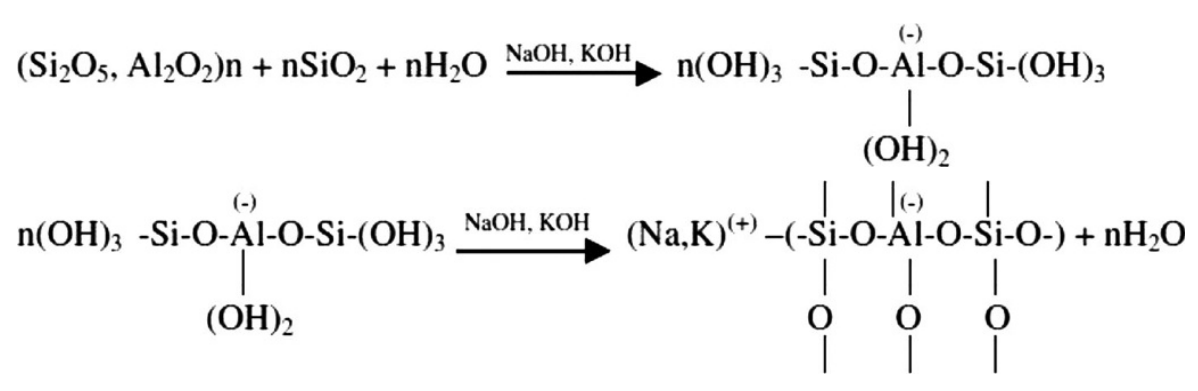

The polymerisation process involves a substantially fast chemical reaction under alkaline condition on $\mathrm{Si}-\mathrm{Al}$ minerals, that results in a three-dimensional polymeric chain and ring structure consisting of $\mathrm{Si}-\mathrm{O}-\mathrm{Al}-\mathrm{O}$ bonds as shown in Eq. (3) (Davidovits 1999):

$$
\mathrm{M}_{\mathrm{n}}\left[-\left(\mathrm{SiO}_{2}\right) \mathrm{z}-\mathrm{AlO}_{2}\right]_{\mathrm{n}} \cdot \mathrm{wH}_{2} \mathrm{O}
$$

where $\mathrm{M}=$ the alkaline element or cation such as potassium, sodium or calcium; the symbol-indicates the presence of a bond, $\mathrm{n}$ is the degree of polycondensation or polymerisation; $\mathrm{z}$ is $1,2,3$, or higher, up to 32 . As mentioned earlier, the above formula for the sodium aluminosilicate complex can also be expressed as $n \mathrm{Na}_{2} \mathrm{O} \cdot \mathrm{Al}_{2} \mathrm{O}_{3} \cdot x \mathrm{SiO}_{2} \cdot y \mathrm{H}_{2} \mathrm{O}$. Combining the above formulations, the formation of the reaction product from the alkali activation of fly ash was expressed in Eq. (4) as

$$
\begin{aligned}
& n\left(\mathrm{Si}_{2} \mathrm{O}_{5} \cdot \mathrm{Al}_{2} \mathrm{O}_{2}\right)+2 n \mathrm{SiO}_{2}+4 n \mathrm{H}_{2} \mathrm{O}+2 \mathrm{NaOH} \\
& \quad \rightarrow n \mathrm{Na}_{2} \mathrm{O} \cdot \mathrm{Al}_{2} \mathrm{O}_{3} \cdot x \mathrm{SiO}_{2} \cdot y \mathrm{H}_{2} \mathrm{O}+\Delta(\text { exothermic })
\end{aligned}
$$

slightly superior to the reference concrete made with PC. Corrosion-resistant concretes were developed by using sodaalkali melt and $\mathrm{NaOH}$. The maximum compressive strength was obtained by a mix containing 49-53 \% slag, 41-45\% fly ash and $7 \% \mathrm{NaOH}$ (Talling and Brandstetr 1995). For the purpose of simplicity in the present study, it is assumed that the calcium silicate hydrate $[\mathrm{C}-\mathrm{S}-\mathrm{H}(\mathrm{S})]$ was produced from the hydration reaction of slag which is equivalent to 'weak' cement due to its latent hydraulic property. The balanced chemical equations for the hydration of slag were then expressed (Eqs. (5a), (5b)) as:

$$
\begin{aligned}
\mathrm{C}_{3} \mathrm{~S}+\left(6.9-\mathrm{n}^{\prime}\right) \mathrm{H} \rightarrow & \mathrm{C}_{n^{\prime}} \mathrm{SH}_{3.9}(\text { or } \mathrm{C}-\mathrm{S}-\mathrm{H}(\mathrm{S})) \\
& +\left(3-\mathrm{n}^{\prime}\right) \mathrm{CH} \\
\mathrm{C}_{2} \mathrm{~S}+\left(5.9-\mathrm{n}^{\prime}\right) \mathrm{H} \rightarrow & \mathrm{C}_{n^{\prime}} \mathrm{SH}_{3.9}(\text { or } \mathrm{C}-\mathrm{S}-\mathrm{H}(\mathrm{S})) \\
& +\left(2-\mathrm{n}^{\prime}\right) \mathrm{CH}
\end{aligned}
$$

It should be noted that due to the assumption that slag behaves as weak cement, in this case the $\mathrm{C}_{3} \mathrm{~S}$ and the $\mathrm{C}_{2} \mathrm{~S}$ contents of the slag was treated individually, instead of the slag as a whole. The following section will discuss the estimation of the volume fractions of the reaction products 


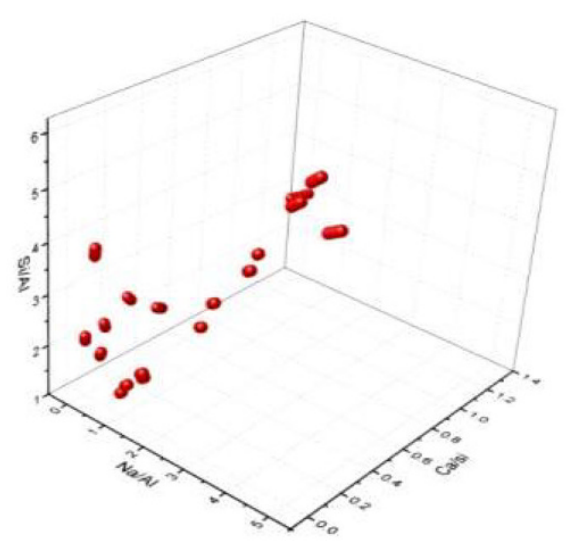

(a) $23^{\circ} \mathrm{C}$

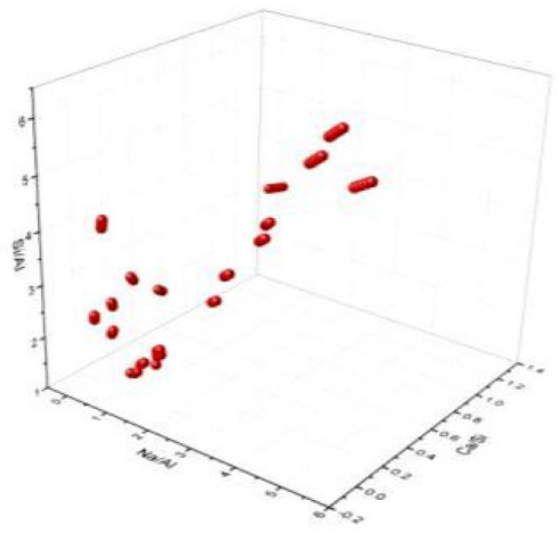

(b) $40^{\circ} \mathrm{C}$

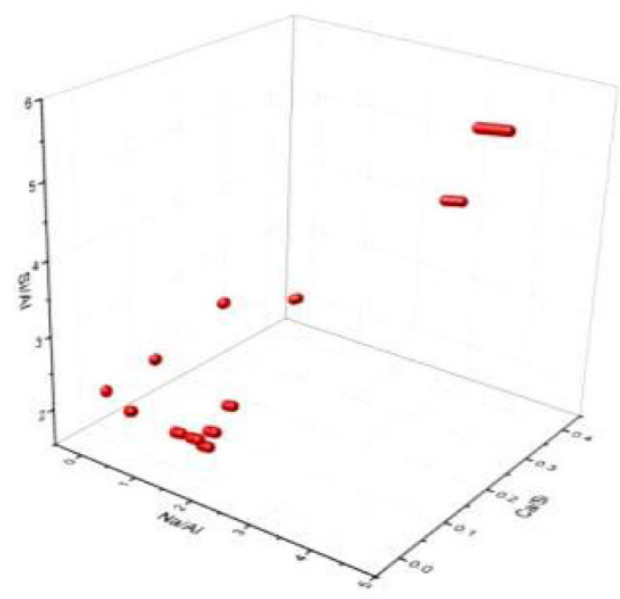

(c) $60^{\circ} \mathrm{C}$

Fig. $43 \mathrm{D}$ plots of $\mathrm{Na} / \mathrm{Al}, \mathrm{Si} / \mathrm{Al}$ and $\mathrm{Ca} / \mathrm{Si}$ atomic ratios for a typical 7-day old $\mathrm{FA} 100 \mathrm{AAB}$ paste at three different curing temperatures: a $23, \mathbf{b} 40$, and $\mathbf{c} 60^{\circ} \mathrm{C}$.

using the stoichiometry of the chemical reactions presented in Eqs. (4) and (5).

\subsubsection{Estimation of Polymer Product Due to Alkali Activation of Fly Ash}

From Eq. (4) it was evident that $n$ moles of $\mathrm{Si}_{2} \mathrm{O}_{5} \cdot \mathrm{Al}_{2} \mathrm{O}_{2}$ (which represented fly ash in the present study) produces $1 \mathrm{~mol}$ of the polymer product. Now, $n$ moles of $\mathrm{Si}_{2} \mathrm{O}_{5} \cdot \mathrm{Al}_{2} \mathrm{O}_{2}$ contains $n$ moles of aluminum oxide. Now, $\mathrm{Si}_{2} \mathrm{O}_{5} \cdot \mathrm{Al}_{2} \mathrm{O}_{2}$ can be rewritten as $2 \mathrm{SiO}_{2} \cdot \mathrm{Al}_{2} \mathrm{O}_{3}$. The oxide composition for the fly ash was obtained from the local plant and they provided the compositions in terms of $\mathrm{SiO}_{2}$ and $\mathrm{Al}_{2} \mathrm{O}_{3}$. So, this minor adjustment was made while writing the formula. Thus, $n$ moles of $\mathrm{Al}_{2} \mathrm{O}_{3}$ produce $1 \mathrm{~mol}$ of the polymer product at full reaction.

Molecular weight (MW) of $\mathrm{Al}_{2} \mathrm{O}_{3}=2 * 27+3 * 16=$ 102 grams per mole.

MW of the polymer product, $n \mathrm{Na}_{2} \mathrm{O} \cdot \mathrm{Al}_{2} \mathrm{O}_{3} \cdot x \mathrm{SiO}_{2} \cdot y \mathrm{H}_{2} \mathrm{O}$ (in terms of $n, x$ and $y)=[(2 * 23+16) * n+(28+$ $2 * 16) * x+(102)+(18) * y]=(62 n+60 x+102+$ $18 y$ ) grams per mole.

So, $102 n$ grams of $\mathrm{Al}_{2} \mathrm{O}_{3}$ produces $(62 n+60 x+102+$ $18 y$ ) grams of $n \mathrm{Na}_{2} \mathrm{O} \cdot \mathrm{Al}_{2} \mathrm{O}_{3} \cdot x \mathrm{SiO}_{2} \cdot y \mathrm{H}_{2} \mathrm{O}$ at full reaction.
The fly ash used for the present study contained $22.73 \%$ $\mathrm{Al}_{2} \mathrm{O}_{3}$ by weight. By unitary method, 100 grams of fly ash used in the present study will produce $\left[\frac{22.73(62 n+60 x+102+18 y)}{102 n}\right]$ grams of $n \mathrm{Na}_{2} \mathrm{O} \cdot \mathrm{Al}_{2} \mathrm{O}_{3} \cdot x \mathrm{SiO}_{2} \cdot y \mathrm{H}_{2} \mathrm{O}$ at full reaction. The specific gravity of the fly ash used was 2.47. Hence $1 \mathrm{cc}$ volume of fly ash contains $2.47 \mathrm{~g}$ of fly ash by weight. So, $1 \mathrm{cc}$ volume of fly ash used will produce $\left[\frac{22.73 \times 2.47(62 n+60 x+102+18 y)}{102 n \times 100}\right]$ grams of $n \mathrm{Na}_{2} \mathrm{O} \cdot \mathrm{Al}_{2} \mathrm{O}_{3} \cdot x \mathrm{SiO}_{2} \cdot y \mathrm{H}_{2} \mathrm{O}$ at full reaction. Since the present study required the volume stoichiometry of the polymerization reaction, the next step was to determine the theoretical volume of $\mathrm{AAB}$ product formed as a result of it. The weight of the AAB product obtained from the above expression was divided by its mass density to compute its volume. The work done by Duxson et al. (2005) showed that the mass density of the AAB reaction product depended on the $\mathrm{Si} / \mathrm{Al}$ ratio of the precursor. For the present study, the $\mathrm{Si} / \mathrm{Al}$ ratio in the precursor is 2.1 . By linear interpolation of the results obtained by Duxson et al. (2005), the mass density of the AAB product for the present study was found to be $1.7,904 \mathrm{gm} / \mathrm{cc}$. So, the volume of $\mathrm{AAB}$ product (in cc) formed by the alkali activation of $1 \mathrm{cc}$ volume of fly ash was found to be 


$$
v_{A A B}=\frac{22.73 \times 2.47(62 n+60 x+102+18 y)}{102 n \times 100 \times 1.7904}
$$

At any given age, let $\alpha_{\mathrm{FA}}$ denote the degree of reaction of the fly ash. Then the volume, $v_{A A B}$, of AAB reaction product formed by the alkali activation of $1 \mathrm{cc}$ of fly ash was expressed as

$$
\begin{aligned}
v_{A A B, \propto} & =\propto_{F A} \times \frac{22.73 \times 2.47(62 n+60 x+102+18 y)}{102 n \times 100 \times 1.7904} \\
& =\frac{\propto_{F A}}{n} \times(0.1906 n+0.1844 x+0.3136+0.0554 y) \mathrm{cc}
\end{aligned}
$$

The total volume of the AAB paste at any degree of reaction, $\propto_{F A}$, consists of the volume of $\mathrm{AAB}$ reaction product in the paste at that instant and also the unreacted residue that is present in the paste. The volume of unreacted residue (in cc) produced by $1 \mathrm{cc}$ of fly ash at any degree of reaction, $\propto_{F A}$ was expressed as

$$
v_{\text {unreacted }}=1-\propto_{F A}
$$

So, the total volume of paste, $v_{\mathrm{hcp}, \mathrm{FA}}$ (in cc) produced by the alkali activation of $1 \mathrm{cc}$ of fly ash at any degree of reaction, $\propto_{F A}$ was

$$
\begin{aligned}
v_{h c p, F A}= & v_{A A B, \propto}+v_{\text {unreacted }} \\
= & \frac{\propto_{F A}}{n} \times(0.1906 n+0.1844 x+0.3136+0.0554 y) \\
& +\left(1-\propto_{F A}\right)
\end{aligned}
$$

So, the volume fraction, $v_{f, A A B}$, of the $\mathrm{AAB}$ reaction product present in the reacted paste at any degree of reaction $\propto_{F A}$ was

$$
v_{f . A A B, \propto}=\frac{v_{A A B, \propto}}{v_{A A B, \propto}+v_{\text {unreacted }}}
$$

Nonlinear optimization technique was used to minimize the difference between the theoretical volume fraction calculated using the above expression and the experimental volume fractions computed using the 3-D plots of the data from SEM/EDS microanalyses. Similar calculations were made when the precursor was made by combining fly ash with slag as either partial or full replacement. The relevant calculations are explained elaborately in the following section.

\subsubsection{Estimation of Polymer Product and $\mathrm{CSH}(\mathrm{S})$ for $\mathrm{P} \%$ Fly Ash Combined with Q \% Slag}

As mentioned earlier, slag is assumed to behave like weak cement. From the volume stoichiometry of slag hydration in Eq. (5a), it was found that 1 volume of $\mathrm{C}_{3} \mathrm{~S}$ produces $\frac{\left(56.08 n^{\prime}+130.2\right) / 1.69}{228 / 3.21}$ volume of $\mathrm{CSH}(\mathrm{S})$ at full hydration. Now, $100 \mathrm{~mL}$ of slag used for the present study contains $52.5 \mathrm{~mL}$ of $\mathrm{C}_{3} \mathrm{~S}$. So, $52.5 \mathrm{~mL}$ of $\mathrm{C}_{3} \mathrm{~S}$ contributes

$$
52.5 \times \frac{\left(56.08 n^{\prime}+130.2\right) / 1.69}{228 / 3.21}
$$

$\mathrm{mL}$ of $\mathrm{C}-\mathrm{S}-\mathrm{H}(\mathrm{S})$ per $100 \mathrm{~mL}$ of the unreacted slag.

Similarly, using Eq. (5b), 1 volume of $\mathrm{C}_{2} \mathrm{~S}$ produces $\frac{\left(56.08 n^{\prime}+132.14\right) / 1.85}{172 / 3.28}$ volume of $\mathrm{C}-\mathrm{S}-\mathrm{H}(\mathrm{S})$ at full hydration. Now, $100 \mathrm{~mL}$ of the slag used for the present study contains $21.7 \mathrm{~mL}$ of $\mathrm{C}_{2} \mathrm{~S}$. So, $\mathrm{C}_{2} \mathrm{~S}$ contributes

$$
21.7 \times \frac{\left(56.08 n^{\prime}+130.2\right) / 1.69}{172 / 3.28}
$$

$\mathrm{mL}$ of $\mathrm{C}-\mathrm{S}-\mathrm{H}(\mathrm{S})$ per $100 \mathrm{~mL}$ of the unreacted slag.

So, at any instant of time, $t$ or any degree of hydration, $\alpha_{\text {slag }}$, the total volume of $\mathrm{CSH}(\mathrm{S})$ due to $\mathrm{C}_{3} \mathrm{~S}$ and $\mathrm{C}_{2} \mathrm{~S}$ hydration, $v_{C-S-H(S)}$ can be obtained by adding the above two expressions. This comes out to be

$$
v_{C S H(S)}=\propto_{\text {slag }} \times\left(0.399 n^{\prime}+0.926\right)
$$

$\mathrm{mL}$ per $1 \mathrm{cc}$ of the unreacted slag.

The details of Eqs. (11)-(13) have been presented in a previous study by Kar et al. (2012b). The next step was to calculate the total volume of the products due to slag hydration. From the study of Chen and Brouwers (2007), it was found that the volume of $\mathrm{CSH}(\mathrm{S})$ was approximately $90 \%$ of the total volume of the hydrated paste. For the sake of simplicity of the present study, the total volume of the hydrated paste due to slag hydration was calculated as

$$
v_{h c p, S G}=1.1 \times v_{C S H(S)}
$$

Now for example, let there be a mixture proportion containing $\mathrm{P} \%$ of fly ash and Q \% of slag (by weight). The total volume of reacted or hydrated paste, $v_{\text {hcp,FA+SG, at any }}$ instant of time was then expressed as the sum of the volume of hydrated paste due to the alkali activation of fly ash and that due to slag hydration.

So,

$$
\begin{aligned}
v_{h c p, F A+S G}= & v_{h c p, F A}+v_{h c p, S G}=\frac{P}{100} \\
\times & \left(\frac{\propto_{F A}}{n} \times(0.1906 n+0.1844 x+0.3136\right. \\
+ & \left.0.0554 y)+\left(1-\propto_{F A}\right)\right) \\
+ & \frac{Q \times 1.1 \times v_{C-S-H(S)}}{100} \\
\text { Or, } v_{h c p, F A+S G}= & \frac{P}{100} \\
& \times\left(\frac{\propto_{F A}}{n} \times(0.1906 n+0.1844 x\right. \\
& \left.+0.3136+0.0554 y)+\left(1-\propto_{F A}\right)\right) \\
& +\frac{Q \times 1.1 \times \propto_{\text {slag }} \times\left(0.399 n^{\prime}+0.926\right)}{100}
\end{aligned}
$$

The volume fraction of the $\mathrm{AAB}$ reaction product with respect to the total paste volume at any instant was expressed as 


$$
\begin{aligned}
v_{f . A A B, \propto} & =\frac{v_{A A B, \propto}}{v_{h c p, F A+S G}} \\
& =\frac{\frac{P \times \propto_{F A}}{100 n} \times(0.1906 n+0.1844 x+0.3136+0.0554 y)}{\frac{P}{100} \times\left(\frac{\propto_{F A}}{n} \times(0.1906 n+0.1844 x+0.3136+0.0554 y)+\left(1-\propto_{F A}\right)\right)+\frac{Q \times 1.1 \times \propto_{\text {slag }} \times\left(0.399 n^{\prime}+0.926\right)}{100}}
\end{aligned}
$$

Similarly, the volume fraction of the C-S-H(S) w.r.t. the total paste volume at any instant was expressed as
The values for degree of reaction of fly ash have been presented in Table 4.

$$
\begin{aligned}
v_{f . C-S-H(S), \propto} & =\frac{v_{C S H(S), \propto}}{v_{h c p, F A+S G}} \\
& =\frac{\frac{Q \times \propto_{s l a g} \times\left(0.399 n^{\prime}+0.926\right)}{100}}{\frac{P}{100} \times\left(\frac{\alpha_{F A}}{n} \times(0.1906 n+0.1844 x+0.3136+0.0554 y)+\left(1-\propto_{F A}\right)\right)+\frac{Q \times 1.1 \times \propto_{s l a g} \times\left(0.399 n^{\prime}+0.926\right)}{100}}
\end{aligned}
$$

Nonlinear optimization technique was used to minimize the difference between the theoretical volume fraction calculated using the above expression and the experimental volume fractions computed using the 3-D plots of the data from SEM/EDS microanalyses. The details about the optimization are explained elaborately in Sect. 3.2. But before that, it is important to discuss the degree of reaction of the precursors in some more detail. In order to validate the test results from the present study, the degree of fly ash reaction values were compared with corresponding values from available literature (Smilauer et al. 2011). It was seen that the experimental values were in close agreement with the data from existing literature (Fig. 5).

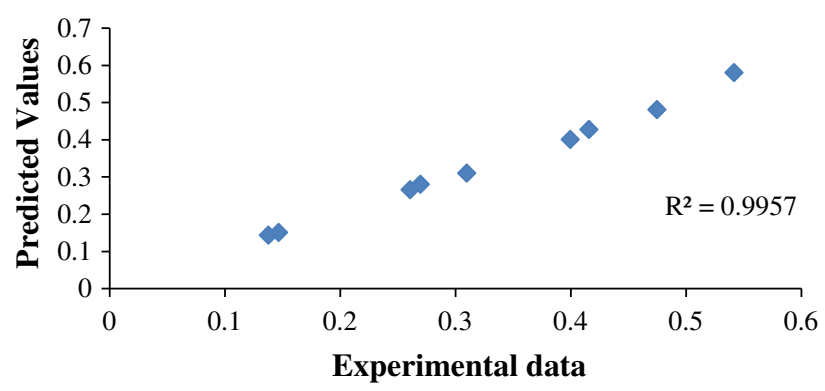

Fig. 5 Correlation between values of degree of reaction of fly ash from present study and those from existing literature.
In the case of slag hydration, however, the values for rate of hydration were obtained from a previous study by Kar et al. (2012b). That study was conducted at constant temperature of $23{ }^{\circ} \mathrm{C}$. From the findings of other researchers, it was observed that the rate of slag hydration remained almost equal even at elevated temperatures (Fernandez-Jimenez and Puertas 1997). The results of the slag degrees of hydration have been summarized in Table 5 .

The optimization technique adopted in order to obtain the chemical composition of the reaction products of the alkali activation of fly ash and/or slag is described in the next section.

\subsection{Optimization Using GAMS}

The unknown parameters that needed to be solved in the present study were the $\mathrm{Na}_{2} \mathrm{O} / \mathrm{Al}_{2} \mathrm{O}_{3}(n), \mathrm{SiO}_{2} / \mathrm{Al}_{2} \mathrm{O}_{3}(x)$, and $\mathrm{H}_{2} \mathrm{O} / \mathrm{Al}_{2} \mathrm{O}_{3}(y)$ ratios in the polymer product formed due to the alkali activation of fly ash and the $\mathrm{Ca} / \mathrm{Si}$ ratio in the case of slag. The parameters were obtained by comparing experimental values with theoretical predictions using a constrained nonlinear least squares approach. Let $t$ denote an index for time. However, the time-dependent parameter was the degree of reaction in case of alkali activation of fly ash and the degree of hydration in case of slag. In the present study, the specimens were studied at three different curing temperatures and for each curing temperature three different ages were selected for the experiments. Hence, for the present study there were $3 * 3=9$ different indices corresponding to $t$. Note that $t$ can take values $1,2,3, \ldots \ldots$, uP to 9

Table 4 Degree of reaction of alkali activated fly ash at different temperatures.

\begin{tabular}{c|c|c|c}
\hline \multirow{2}{*}{ Temperature $\left({ }^{\circ} \mathrm{C}\right)$} & \multicolumn{2}{|c}{ Age } & 90 days \\
\cline { 2 - 4 } & 7 days & 28 days & 0.416 \\
\hline \hline 23 & 0.138 & 0.261 & 0.475 \\
\hline 40 & 0.147 & 0.270 & 0.542 \\
\hline 6
\end{tabular}


Table 5 Degree of reaction of alkali activated slag at different temperatures.

\begin{tabular}{c|c|c|c}
\hline \multirow{2}{*}{ Temperature $\left({ }^{\circ} \mathrm{C}\right)$} & \multicolumn{3}{|c}{ Age } \\
\cline { 2 - 4 } & 7 days & 28 days & 90 days \\
\hline \hline 23 & $0.25(0.2-0.3)$ & $0.35(0.3-0.4)$ & $0.55(0.4-0.6)$ \\
\hline 40 & $0.25(0.2-0.3)$ & $0.35(0.3-0.4)$ & $0.55(0.4-0.6)$ \\
\hline 60 & $0.25(0.2-0.3)$ & $0.35(0.3-0.4)$ & $0.55(0.4-0.6)$ \\
\hline
\end{tabular}

corresponding to 7,28 and 90 days at each of 23,40 and $60{ }^{\circ} \mathrm{C}$. In case of slag, the degree of hydration was found to be more or less independent of the curing temperature. The index $t$ can take the values 1,2 , and, 3 corresponding to 7 , 28, and 90 days.

Let $v_{f, A A B}^{\text {exp } t}$ and $v_{f, C S H(S)}^{\text {exp } t}$ denote the experimentally determined volume fractions of the $\mathrm{AAB}$ reaction product and $\mathrm{CSH}(\mathrm{S})$ respectively at time $t$. Let $v_{f, A A B}^{\text {pred,t }}$ and $v_{f, C S H(S)}^{\text {pred,t }}$ denote the predicted volume fractions of the $\mathrm{AAB}$ reaction product and $\mathrm{CSH}(\mathrm{S})$ respectively at time $t$. For the FA 100 mixture proportion, the values of $n, x$, and, $y$ can be determined by solving the constrained nonlinear optimization problem.

$$
\begin{aligned}
& \min \sum_{t=1}^{9}\left(v_{f, A A B}^{\text {exp }, t}-v_{f, A A B}^{\text {pred }, t}\right)^{2} \\
& 1 \leq n \leq 1.6 \\
& 2 \leq x \leq 3.5 \\
& 3 \leq y \leq 7
\end{aligned}
$$

For fly ash combined with slag, knowing the volume fraction of AAB at time $t, v_{f, C S H(S)}^{t}$ can be determined using the formula provided in Eq. (19). The values of $n^{\prime}$ and $\alpha^{\prime}, t$ can be determined by minimizing the sum of square differences between $v_{f, C S H(S)}^{\text {exp } t}$ and $v_{f, C S-(S)}^{\text {pred,t }}$ as shown below.

$$
\begin{aligned}
& \min \sum_{t=1}^{3}\left(v_{f, \operatorname{CSH}(S)}^{\text {exp } t}-v_{f, \operatorname{CSH}(S)}^{\text {pred } t}\right)^{2} \\
& 1.1 \leq n^{\prime} \leq 1.4 \\
& 0.2 \leq \alpha^{\prime}, 1 \leq 0.3 \\
& 0.3 \leq \alpha^{\prime}, 2 \leq 0.4 \\
& 0.4 \leq \alpha^{\prime}, 3 \leq 0.5
\end{aligned}
$$

The nine different values of the time index, $t$, in case of FA 100 were represented by the degrees of reaction of fly ash at each corresponding age. Hence, the optimization scheme produced nine different equations for three unknowns. The formulations for each of these equations were coded in the GAMS (Rosenthal 2008) and solved using the in-built CONOPT solver (Drud 2004) - a popular solver for nonlinear optimization problems (Baazara et al. 2006). The problem at hand was ideally a minimization problem - the optimized values for $n, x$, and, $y$ were taken as those for which the difference between the predicted and the experimental values were the minimum. The output from GAMS was the set of values of $n, x, y$ and, $n^{\prime}$ - for which the differences between the experimental and theoretical values of the volume fractions were minimum. The optimization technique produced the following solutions: (i) $n=1.230$, (ii) $x=2.634$, and, (iii) $y=4.673$. The $n^{\prime}$ value of 1.4 for each $\mathrm{AAB}$ mix containing partial or full replacement of fly ash with slag were obtained from a previous study by Kar et al. (2012b). The first three solutions provided the optimized chemical composition for the AAB activation reaction. The solution for $n^{\prime}$ provided the optimized chemical composition for $\mathrm{CSH}(\mathrm{S})$ when slag was present in the precursor. The results, obtained using the optimization technique, were then used to compute the volume fractions of the reaction products. Those results were then compared with experimental data to validate the technique. The comparisons have been shown in the following section for alkali activations of both fly ash and slag.

\section{Discussions and Observations from Experiments and Analytical Techniques}

\subsection{Comparison of Experimental and Predicted Data for Reacted AAB Paste Product and CSH(S) Using Results from Optimization}

In this section, comparisons have been presented between the predicted and experimental values of the volume fraction of the reaction products due to alkali activation of fly ash and that of slag. The volume fractions have been denoted by $v_{f, A A B}$ and $v_{f, C S H(S)}$, respectively. The volume fractions in case of FA 100 AAB were computed based on the 30 randomly chosen experimental data points mentioned in Sect. 3. For the combined FA + SG cases, however, all 90 experimental data points were available for comparison with predicted values of the volume fractions.

From Fig. 6a, it was observed that the predicted and experimental values of $v_{f, A A B}$ were in close agreement with each other for all the mixes at each of three different curing temperatures. The volume fractions of the AAB were found to decrease with increasing slag content as expected. $R^{2}$ value representing the correlation between the experimental and the predicted volume fractions was 0.9976. From Fig. 6b, it was observed that the predicted and experimental values of $v_{f, C S H(S)}$ were also in close agreement with each other. The volume fractions of the $\mathrm{CSH}(\mathrm{S})$ were found to increase with increasing slag content as expected. $R^{2}$ value 

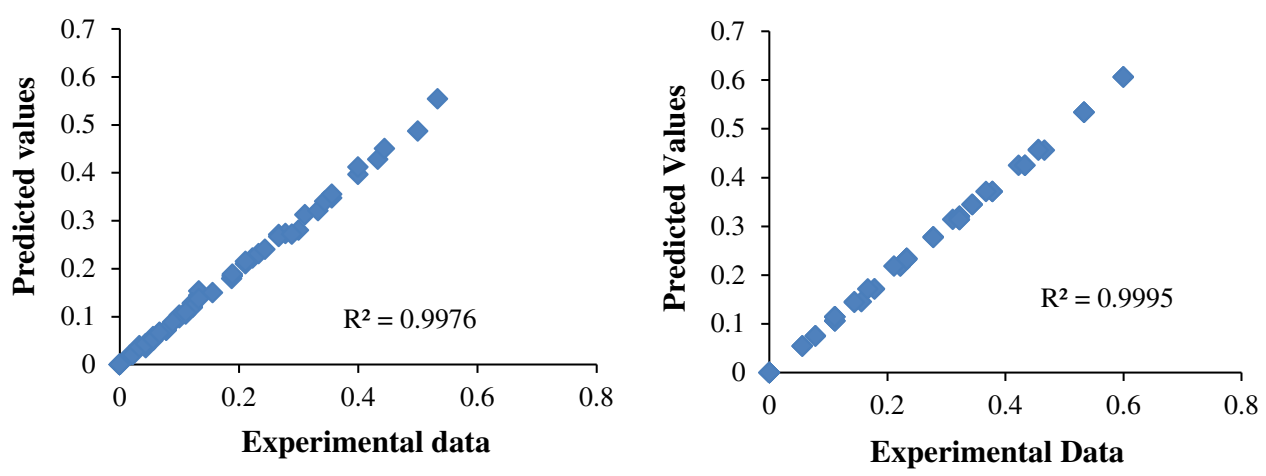

Fig. 6 Correlation between predicted and experimental values of a $v_{f, A A B}$ and $\mathbf{b} v_{f, C S H(S)}$.

representing the correlation between the experimental and the predicted volume fractions was 0.9995 . In the next section, the observations on variation of phase volumes with time have been presented for different combinations of fly ash and slag at different temperatures.

\subsection{Variation of Reacted AAB Paste Product} and $\mathrm{C}-\mathrm{S}-\mathrm{H}(\mathrm{S})$ and the Total Hydrated Paste Volumes with Time for Different Combinations of Fly Ash and Slag at Different Temperatures

From Fig. 7, it was observed that the volume fractions of the $\mathrm{AAB}$ and $\mathrm{CSH}(\mathrm{S})$ increase with age for FA $100 \mathrm{mix}$, which is thought to be the reason behind the development of compressive strength at the specimen level. It was also observed that the increase in curing temperature resulted in an increase in the development of the volume fractions of the $\mathrm{AAB}$ and $\mathrm{CSH}(\mathrm{S})$. This phenomenon corresponded to the increasing rate of compressive strength development with increase in curing temperature. It was observed that the volume fractions of the $\mathrm{AAB}$ and $\mathrm{CSH}(\mathrm{S})$ increase with age for all mixes, which is thought to be the reason behind the development of compressive strength at the specimen level. It was also observed that the increase in curing temperature resulted in an increase in the development of the volume fractions of the $\mathrm{AAB}$ and $\mathrm{CSH}(\mathrm{S})$. This led to the increasing rate of compressive strength development with increase in curing temperature and the data have been presented in Table 6.

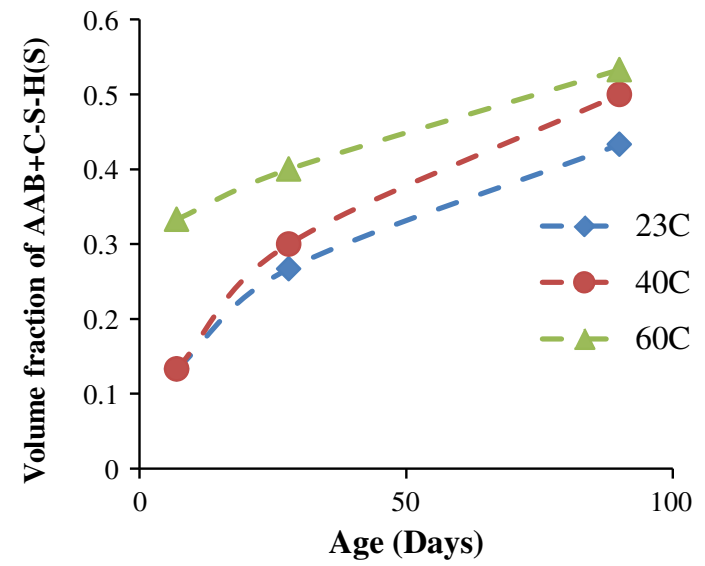

The summary and conclusions based on the observations and discussions in the present study have been presented in the following section.

\section{Summary and Conclusions}

- XRD diffractograms revealed the presence of primarily amorphous phases in the AAB microstructure along with the presence of quartz, mullite, analcime and hydroxy sodalite which were identified by their characteristic peaks.

- FTIR spectra showed the presence of $\mathrm{Si}-\mathrm{O}-\mathrm{Si}$ as well as $\mathrm{Si}-\mathrm{O}-\mathrm{Al}$ bonds and the presence of unreacted raw materials in microstructure of the AAB. The progress of reaction with increasing temperature or addition of $\mathrm{Ca}^{2+}$ ions through slag was also visible.

- SEM images showed that in general, the microstructure of the FA 100 AAB specimens was highly inhomogeneous and primarily made up of the reaction product resulting from the alkali activation - a sodium aluminosilicate gel that gave rise to the cementitious matrix. When slag was added, the lighter areas on the images indicated the $\operatorname{CSH}(\mathrm{S})$ phase formed due to the hydration of slag. CSH(S) was identified through SEM morphology from their fibrous to irregular grains forming reticular network.

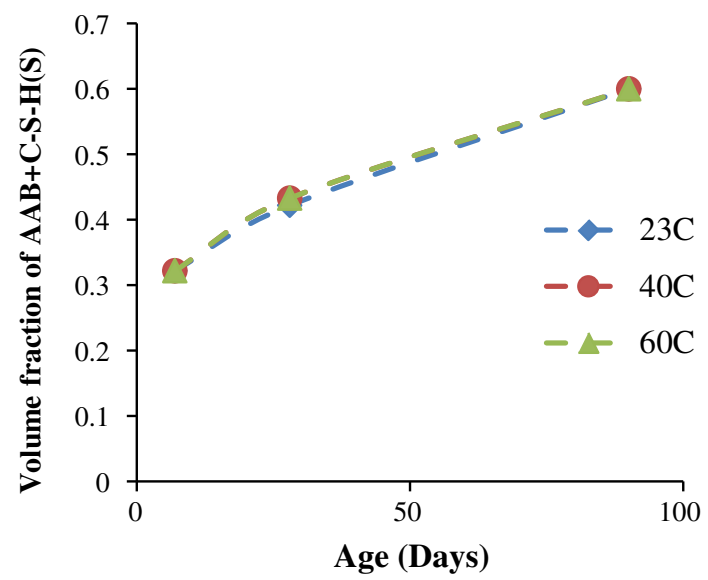

Fig. 7 Volume fraction of $A A B+C S H(S)$ pastes for a FA 100 and b SG 100 at different temperatures. 
Table 6 Volume fractions of reacted phases of $\mathrm{AAB}\left(v_{f, A A B}+v_{f, C S H(S)}\right)$ at different ages for all mixture proportions cured at different temperatures.

\begin{tabular}{|c|c|c|c|c|}
\hline \multirow[t]{2}{*}{ Mix } & \multirow[t]{2}{*}{ Age (days) } & \multicolumn{3}{|c|}{$v_{f, A A B}+v_{f, C S H(S)}$} \\
\hline & & $23{ }^{\circ} \mathrm{C}$ & $40^{\circ} \mathrm{C}$ & $60^{\circ} \mathrm{C}$ \\
\hline \multirow[t]{3}{*}{ FA 100} & 7 & 0.133 & 0.133 & 0.333 \\
\hline & 28 & 0.267 & 0.300 & 0.400 \\
\hline & 90 & 0.433 & 0.500 & 0.533 \\
\hline \multirow[t]{3}{*}{ FA 85 SG 15} & 7 & 0.178 & 0.178 & 0.323 \\
\hline & 28 & 0.301 & 0.311 & 0.422 \\
\hline & 90 & 0.467 & 0.511 & 0.555 \\
\hline \multirow[t]{3}{*}{ FA 70 SG 30} & 7 & 0.211 & 0.211 & 0.322 \\
\hline & 28 & 0.332 & 0.345 & 0.433 \\
\hline & 90 & 0.500 & 0.533 & 0.567 \\
\hline \multirow[t]{3}{*}{ FA 50 SG 50} & 7 & 0.245 & 0.256 & 0.323 \\
\hline & 28 & 0.355 & 0.355 & 0.422 \\
\hline & 90 & 0.533 & 0.555 & 0.588 \\
\hline \multirow[t]{3}{*}{ FA 30 SG 70} & 7 & 0.266 & 0.277 & 0.322 \\
\hline & 28 & 0.389 & 0.400 & 0.433 \\
\hline & 90 & 0.567 & 0.588 & 0.589 \\
\hline \multirow[t]{3}{*}{ FA 15 SG 85} & 7 & 0.295 & 0.300 & 0.322 \\
\hline & 28 & 0.422 & 0.411 & 0.423 \\
\hline & 90 & 0.589 & 0.589 & 0.600 \\
\hline \multirow[t]{3}{*}{ SG 100} & 7 & 0.322 & 0.322 & 0.322 \\
\hline & 28 & 0.422 & 0.433 & 0.433 \\
\hline & 90 & 0.600 & 0.600 & 0.600 \\
\hline \multirow[t]{3}{*}{ FA 100 p 15} & 7 & 0.133 & 0.133 & 0.333 \\
\hline & 28 & 0.267 & 0.300 & 0.400 \\
\hline & 90 & 0.433 & 0.500 & 0.533 \\
\hline \multirow[t]{3}{*}{ FA 100 p30 } & 7 & 0.133 & 0.133 & 0.333 \\
\hline & 28 & 0.267 & 0.300 & 0.400 \\
\hline & 90 & 0.433 & 0.500 & 0.533 \\
\hline \multirow[t]{3}{*}{ FA 100 p60 } & 7 & 0.133 & 0.133 & 0.333 \\
\hline & 28 & 0.267 & 0.300 & 0.400 \\
\hline & 90 & 0.433 & 0.500 & 0.533 \\
\hline
\end{tabular}

- EDS analysis showed that the matrix primarily consisted of the phases containing $\mathrm{Na}-\mathrm{Si}-\mathrm{Al}$ in the bulk region in case of the specimens where fly ash was the main precursor. In addition to $\mathrm{Na}, \mathrm{Si}$ and $\mathrm{Al}$, traces of $\mathrm{Fe}, \mathrm{Ca}$, $\mathrm{K}$ and $\mathrm{Mg}$ were also observed in these specimens. The trace elements represented the unreacted fly ash phases, which did not dissolve during alkali activation. When slag was present in greater amounts, the presence of $\mathrm{Ca}^{2+}$ was more prominent.

- The degree of reaction of fly ash when activated with alkaline solution was found to increase appreciably with increase in curing temperature. However, in case of slag, the degree of reaction remained more or less independent of curing temperature.

- The predicted and experimental values of the volume fractions of $\mathrm{AAB}$ as well as $\mathrm{CSH}(\mathrm{S})$ were in close agreement with each other showing the accuracy of the combined volume stoichiometry and statistical optimization technique.

- The result will ultimately help to estimate the paste volumes of various unknown AAB mixtures produced from different sources of fly ash and slag. Also the 
technique can be extended for other sources of hybrid precursors containing both aluminosilicate and calcium ion sources.

\section{Acknowledgments}

Special thanks are due to the American Society of Civil Engineers (ASCE) for providing the 2012 ASCE Freeman Fellowship to the first author in support of this research. The authors gratefully acknowledge Arrow Concrete for donating fly ash and slag, and PQ Corporation for providing the sodium silicate solution used in the present study. The authors would also like to acknowledge the Shared Research Facilities at West Virginia University, for allowing usage of the microanalysis equipment.

\section{Open Access}

This article is distributed under the terms of the Creative Commons Attribution License which permits any use, distribution, and reproduction in any medium, provided the original author(s) and the source are credited.

\section{References}

ASTM 7777C618. (2013). Standard specification for coal fly ash and raw or calcined natural pozzolan for use in concrete. Annual book of ASTM standards, concrete and aggregates, 04.02. American Society for Testing and Materials.

ASTM C989. (2013). Standard specification for slag cement for use in concrete and mortars. Annual book of ASTM standards, concrete and aggregates, 04.02. American Society for Testing and Materials.

ASTM C33 M-13. (2013). Standard specification for concrete aggregates. Annual book of ASTM standards, concrete and aggregates, 04.02. American Society for Testing and Materials.

ASTM C494 Type F. (2013). Specification for chemical admixtures for concrete. Annual book of ASTM standards, concrete and aggregates, 04.02. American Society for Testing and Materials.

Barbosa, V. F. F., Mackenzie, K. J. D., \& Thaumaturgo, C. (2000). Synthesis and thermal behaviour of potassium sialate geopolymers. Materials Letters, 57, 1477-1482.

Bazaara, M. S., Sherali, H. D., \& Shetty, C. M. (2006). Nonlinear programming: Theory and algorithms. Hoboken, NJ: Wiley.

Breck, D. W. (1974). Zeolite molecular sieves, structure, chemistry and use. New York, NY: Wiley.

Chen, W., \& Brouwers, H. J. H. (2007). The hydration of slag, part 1: Reaction models for alkali-activated slag. Journal Materials Science, 42, 428-443.
Davidovits, J. (1982). Mineral polymers and methods of making them. US Patent 4,349,386.

Davidovits, J. (1983). Geopolymer chemistry and properties. Proceedings of geopolymer'88. Compiegne, France, 1-3, June 1988.

Davidovits, J. (1988). Geopolymers of the first generation: SILIFACEProcess. In: J. Davidovits, \& J. Orlinski (Eds.), Proceedings of the 1st international conference on geopolymer '88, Vol. 1, Compiegne, France.

Davidovits, J. (1991). Geopolymers: Inorganic polymeric new materials. Journal of Thermal Analysis, 37, 1633-1656.

Davidovits, J. (1994). Geopolymers: Inorganic polymeric new materials. Journal of Materials Education, 16, 91-139.

Davidovits, J. (1999). Geopolymeric reactions in the economic future of cements and concretes: world-wide mitigation of carbon dioxide emission. In: J. Davidovits, R. Davidovits, \& C. James (Eds.), Proceedings of the 2nd international conference on geopolymer'99. Saint Qunentin, France, June 30-July 2, pp. 111-121.

De Silva, P., Sagoe-Crenstil, K., \& Sirivivatnanon, V. (2007). Kinetics of geopolymerization: Role of $\mathrm{Al}_{2} \mathrm{O}_{3}$ and $\mathrm{SiO}_{2}$. Cement and Concrete Research, 37, 512-518.

Drud, A. (2010). CONOPT user guide. Bagsvaerd, Denmark: ARKI Consulting and Development A/S. http://www.gams. com/dd/docs/solvers/conopt.pdf. Last Accessed 14th August 2013.

Duxson, P., Lukey, G. C., Separovic, F., \& van Deventer, J. S. J. (2005). Effect of alkali cations on aluminium incorporation in geopolymeric gels. Industrial and Engineering Chemistry Research, 44, 832-839.

Famy, C., Brough, A. R., \& Taylor, H. F. W. (2003). The C-S-H gel of Portland cement mortars: Part I. The interpretation of energy-dispersive $\mathrm{X}$-ray microanalyses from scanning electron microscopy, with some observations on C-S-H, $\mathrm{AFm}$ and AFt phase compositions. Cement and Concrete Research, 23, 1389-1398.

Feng, X., Garboczi, E. J., Bentz, D. P., Stutzman, P. E., \& Mason, T. O. (2004). Estimation of the degree of hydration of blended cement pastes by a scanning electron microscopy point-count procedure. Cement and Concrete Research, 34(10), 1787-1793.

Fernandez-Jimenez, A., de la Torre, A. G., Palomo, A., LopezOlmo, G., Alonso, M. M., \& Aranda, M. A. G. (2006). Quantitative determination of phases in the alkaline activation of fly ash. Part II: Degree of reaction. Fuel, 85, 1960-1969.

Fernandez-Jimenez, A., \& Puertas, F. (1997). Alkali-activated slag cements: Kinetic studies. Cement and Concrete Research, 27(3), 359-368.

Kamhangrittirong, P., Suwanvitaya, P., Suwanvitaya, P., \& Chindaprasirt, P. (2007). Green binder technology development using fly ash based geopolymer. JSPS-DOST international symposium on environmental engineering, symposium on harmonizing infrastructure development with the environment, Phillipines.

Kar, A., Halabe, U. B., Ray, I., \& Unnikrishnan, A. (2013). Nondestructive characterizations of alkali activated fly ash and/or slag concrete. European Scientific Journal, 9(24), $52-74$. 
Kar, A., Ray, I., Unnikrishnan, A., \& Davalos, J. F. (2012a). Estimation of C-S-H and calcium hydroxide for cement pastes containing slag and silica fume. Construction and Building Materials, 30, 505-515.

Kar, A., Ray, I., Unnikrishnan, A., \& Davalos, J. F. (2012b). Microanalysis and optimization-based estimation of C-SH contents of cementitious systems containing fly ash and silica fume. Cement \& Concrete Composites, 34, 419-429.

Kupwade-Patil, K., \& Allouche, E. (2011). Effect of alkali silica reaction (ASR) in Geopolymer Concrete. World of Coal Ash (WOCA) conference, May 9-12, Devnver, CO, USA.

Lee, W. K. W., \& van Deventer, J. S. J. (2002). Effects of anions on the formation of aluminosilicate gel in geopolymers. Industrial and Engineering Chemistry Research, 41(18), 4550-4558.

Lloyd, R. R., Provis, J. L., \& van Deventer, J. S. J. (2009). Microscopy and microanalysis of inorganic polymer cements. 2: The gel binder. Journal of Materials Science, 44(2), 620-631.

Muzek, M. N., Zelic, J., \& Jozic, D. (2012). Microstructural characteristics of geopolymers based on alkali-activated fly ash. Chemical and Biochemical Engineering Quarterly, 26(2), 89-95.

Provis, J. L., \& van Deventer, J. S. J. (2009). Geopolymers: Structure, processing, properties and industrial applications. Oxford: Woodhead; Boca Raton, FL: CRC Press.

Rees, C. A. (2007). Mechanisms and kinetics of gel formation in geopolymers. Ph.D. Thesis submitted to the Department of Chemical and Biomolecular Engineering, University of Melbourne.

Rees, C., Lukey, G. C., \& Van Deventer, J. S. J. (2004). The role of solid silicates on the formation of geopolymers derived from coal ash. International symposium of research students on material science and engineering, December
20-22, Chennai, India, Department of Metallurgical and Materials Engineering, Indian Institute of Technology Madras.

Rosenthal, R. E. (2008). GAMS - A user guide. Washington DC: Gams Development Corporation.

Sakulich, A. R. (2009). Characterization of environmentallyfriendly alkali activated slag cements and ancient building materials. Ph.D. Thesis, Drexel University, Philadelphia, PA.

Shi, C., Krivenko, P., \& Roy, M. (2006). Alkali-activated cements and concretes. London: Taylor \& Francis.

Skvara, F., Kopecky, L., Nemecek, J., \& Bittnar, Z. (2006). Microstructure of geopolymer materials based on fly ash. Cermaics-Silikaty, 50, 208-215.

Smilauer, V., Hlavacek, P., Skvara, F., Sulc, R., Kopecky, L., \& Nemecek, J. (2011). Micromechanical multiscale model for alkali activation of fly ash and metakaolin. Journal of Materials Science. doi:10.1007/s10853-011-5601-x.

Smith, J. W., \& Comrie, D. C. (1988). Geopolymeric building materials in third world countries. In: J. Davidovits \& J. Orlinski (Eds.), Proceedings of the 1st international conference of geopolymer'88, Vol. 1, Compiegne, France, 1-3 June, pp. 89-92.

Talling, B., \& Brandstetr, J. (1995). Clinker-free concrete based on alkali activated slag. In S. L. Sarkar \& S. N. Ghosh (Eds.), Progress in cement and concrete: Mineral admixtures in cement and concrete. New Delhi, India: Akademia Books International.

Taylor, H. F. W. (1997). Cement Chemistry (2nd ed.). Thomas Telford.

Van Jaarsveld, J. G. S. (2000). The physical and chemical characterisation of fly ash based geopolymers. $\mathrm{PhD}$ Thesis, Department of Chemical Engineering, University of Melbourne, Australia. 